\title{
Association between rs2735839 and Serum Prostate-specific Antigen Level Regarding Risk of Prostate Cancer in Iranian Population
}

\author{
Behnaz Beikzadeh', Seyed Abdolhamid Angaji²,* (D), Maryam Abolhasani ${ }^{3}$ \\ ${ }^{1}$ MSc in Genetics, Department of Cell and Molecular Biology, School of Biological Sciences, Kharazmi University, Tehran, \\ Iran \\ ${ }^{2}$ Assistant Professor, Department of Cell and Molecular Biology, Faculty of Biological Sciences, Kharazmi University, \\ Tehran, Iran \\ ${ }^{3}$ Associate Professor, Department of Pathology, School of Medicine, Iran University of Medical Sciences, Tehran, Iran \\ * Corresponding Author: Seyed Abdolhamid Angaji, Department of Cell and Molecular Biology, School of Biological \\ Sciences, Kharazmi University, Tehran, Iran.Email: angaji@khu.ac.ir
}

\begin{tabular}{|c|c|}
\hline & Abstract \\
\hline $\begin{array}{l}\text { Received: } 06.01 .2019 \\
\text { Accepted: } 13.04 .2019\end{array}$ & $\begin{array}{l}\text { Background and Objective: Prostate cancer is among the five common } \\
\text { cancers in males. It is second cancer in terms of the age-standardized rate }\end{array}$ \\
\hline \multirow[t]{2}{*}{$\begin{array}{l}\text { How to Cite this Article: } \\
\text { Beikzadeh B, Angaji SA, } \\
\text { Abolhasani M. Association } \\
\text { between rs2735839 and Serum } \\
\text { Prostate-specific Antigen Level } \\
\text { Regarding Risk of Prostate } \\
\text { Cancer in Iranian Population. } \\
\text { Avicenna J Clin Med. 2019; } \\
\text { 26(1): 12-19. DOI: 10.29252/ } \\
\text { ajcm.26.1.12 }\end{array}$} & $\begin{array}{l}\text { is located on chromosome } 19 \mathrm{q} 13.33 \text { at } 600 \text { base pairs of the KLK3 gene } \\
\text { untranslatable region. This gene which codes prostate-specific antigen } \\
\text { (PSA) is used in the screening and diagnosis of prostate cancer. The purpose } \\
\text { of this study was to evaluate the association between this polymorphism and } \\
\text { prostate adenocarcinoma with PSA. } \\
\text { Materials and Methods: This case-control study included } 103 \text { and } 100 \\
\text { patients with prostate adenocarcinoma and benign prostatic hyperplasia } \\
\text { (BPH) as case and control groups, respectively. Tetra-primer amplification } \\
\text { refractory mutation system-polymerase chain reaction was used to determine } \\
\text { the genotype of each participant regarding rs } 2735839 \text { polymorphism. } \\
\text { Results: There was a significant difference between the adenocarcinoma } \\
\text { prostate and BPH groups regarding genotype frequency AG+AA (OR [95\% } \\
\text { CI]=4.991 [2.475-10.065], P=0.00). According to the results of statistical } \\
\text { analysis, a significant difference was observed between the adenocarcinoma } \\
\text { and BPH groups in terms of allele frequency (OR [95\% CI]=3.927 [2.085- } \\
7.397] \text {, P=0.00). Moreover, There was a significant difference between } \\
\text { rs } 2735839 \text { and PSA regarding the genotype frequency polymorphism } \\
\text { (P=0.011). } \\
\text { Conclusion: The results indicate that rs } 2735839 \text { is associated with an } \\
\text { increased risk of prostate cancer in Iranian population. It is worth noting that } \\
\text { a significant difference was found between the distribution of allele A and } \\
\text { that of allele G with PSA levels of }>10 \text {. }\end{array}$ \\
\hline & $\begin{array}{l}\text { Keywords: Gamma-seminoprotein, Kallikrein 2, Prostatic Hyperplasia, } \\
\text { Single Nucleotide Polymorphism }\end{array}$ \\
\hline
\end{tabular}




\title{
مطالعه همر اهى بين rs2735839 با خطر ابتلا به آدنوكارسينوماى يروستات و سطح سر مى PSA در جمعيت ايران
}

\author{
بهناز بيكز اده'، سيد عبدالحميد انكجى r." (DD ، مريم ابوالحسنى '
}

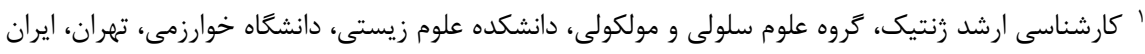

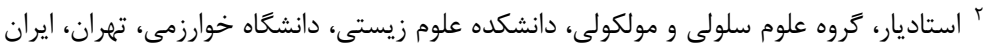

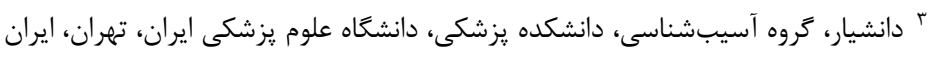

* نويسنده مسئول: سيد عبدالحميد انكَجى، كروه علوم سلولى و مولكولى، دانشكده علوم زيستى، دانشعاه خوارزمى، تهران، ايران.

ايميل:khu.ac.ir

\begin{tabular}{|c|c|}
\hline جكيده & \\
\hline 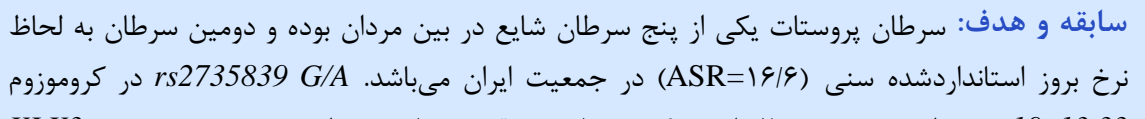 & 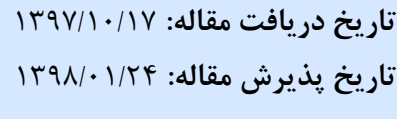 \\
\hline 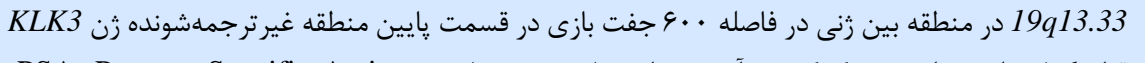 & \\
\hline قرار كرفته است. اين رن كدكننده آنتىخن اختصاصى يروستات (PSA: Prostate Specific Antigen) & لتمكى حقوق نشفر براى دانشكاه علوم \\
\hline مىباشد و از آن در غربالكرى و تشخيص اين نوع سرطان استفاده مى كردد. با توجه به موارد بيانشده، مطالعه & \\
\hline حاضر با هدف بررسى همراهى اين يلىمورفيسم با آدنوكارسينوماى يروستات و PSA انجام شد. & \\
\hline مواد و روش ها: مطالعه مورد- شاهدى حاضر شامل ץ ·ـ فرد مبتلا به آدنوكارسينوماى يروستات بهعنوان & \\
\hline كروه مورد و . . ا فرد مبتلا به هاييريلازى خوشخيم يروستات (BPH: Benign Prostatic Hyperplasia) & \\
\hline Tetra-Primer ) Tetra-primer ARMS-PCR بهنوان كروه كنترل بود. در اين مطالعه از روش & \\
\hline (Amplification Refractory Mutation System-Polymerase Chain Reaction بهمنظور تعيين & \\
\hline رنوتايب هريك از افراد شركت كننده براى يلىمورفيسم rs2735839 استفاده كرديد. & \\
\hline يافتهها: بين فراوانى رنوتيبى AG+AA در كروه آدنوكارسينوماى يروستات با BPH اختلاف معنادارى وجود & \\
\hline 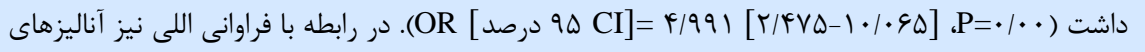 & \\
\hline 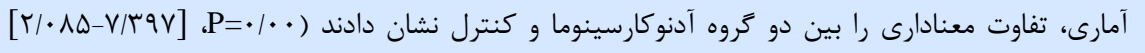 & \\
\hline 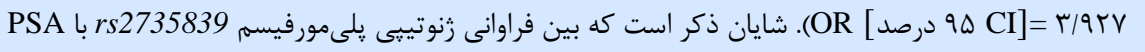 & \\
\hline 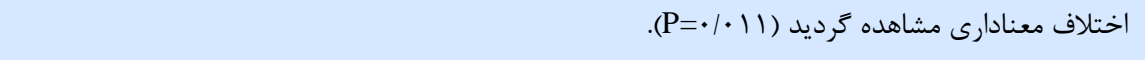 & \\
\hline نتيجه كيرى: نتايج مطالعه حاضر در ارتباط با rs2735839 نشاندهنده همراهى اين يلىمورفيسم با خطر & \\
\hline سرطان بروستات در جمعيت ايران بودند. شايان ذكر است كه در اين مطالعه اختلاف معنادارى بين توزيع & \\
\hline فراوانى الل A نسبت به الل G با سطح PSA>10 مشاهده كرديد. & \\
\hline وازًٔان كليدى: جندشكلى تكنوكلئوتيدى، كاليكرئين ؟، كاما سمينويروتئين، هايبريلازى يروستات & \\
\hline
\end{tabular}

مقدمه

كمترين نرخ آن در كشورهاى آسيايى كزارش شده است [هـ].

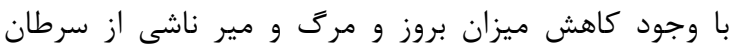

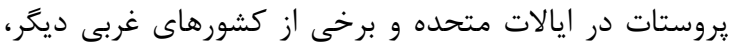

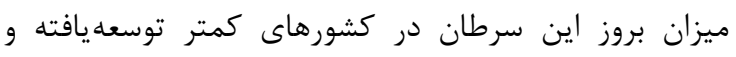

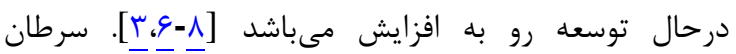

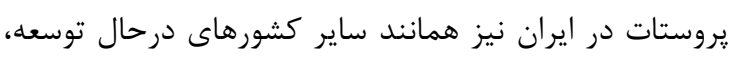

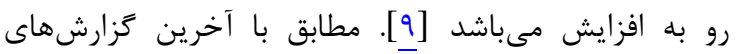

سرطان يروستات يكى از پينج سرطان شايع از نظر نرخ بروز

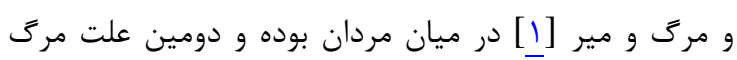

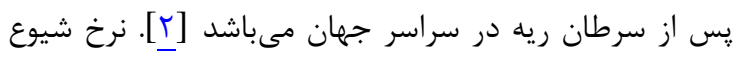

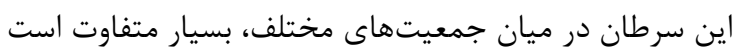

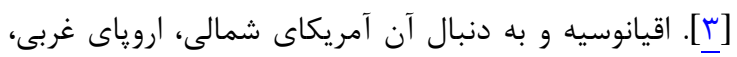

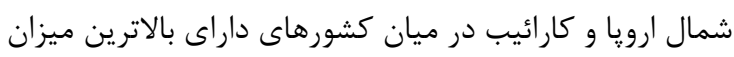

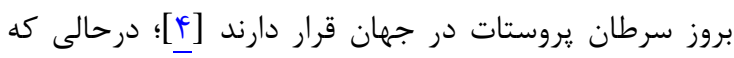


225543369) و در حقيقت در نزديكى انتهاى 'r اين زن قرار

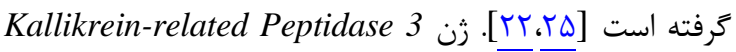

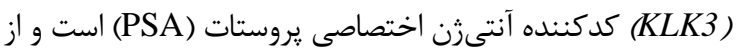

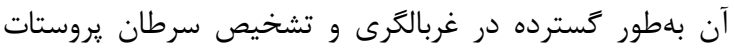

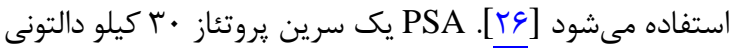

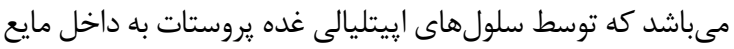
سمينال و خون ترشح مى كردد. PSA ماده مهاركننده حركت

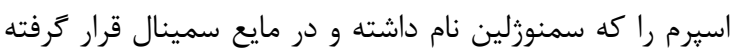

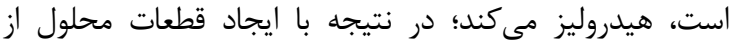

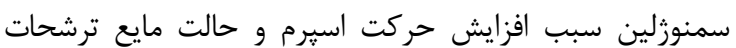

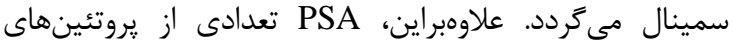
تنظيم كننده رشد كه در رشد و نجات سلودلهائ سردائ سرطانى اهميت

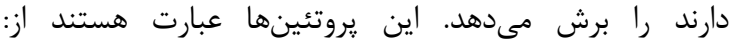

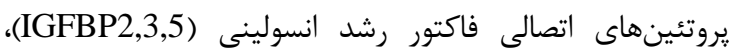

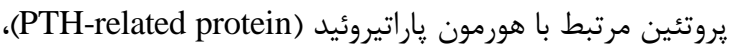
latent TGF- 32

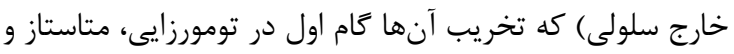

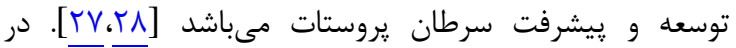

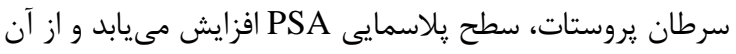

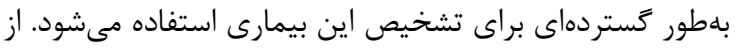

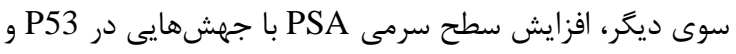

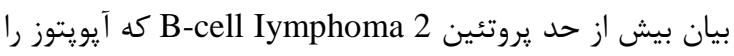

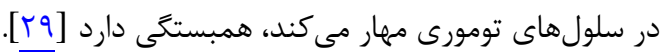

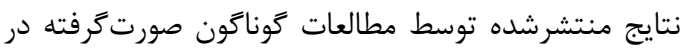

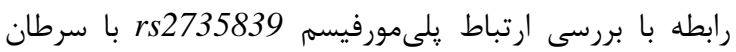

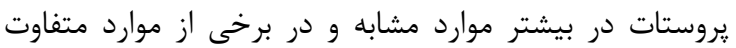

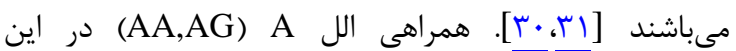

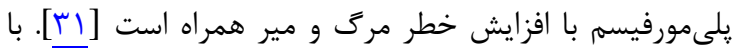

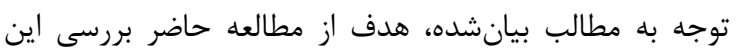

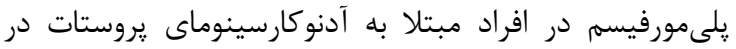

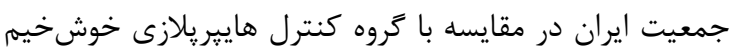

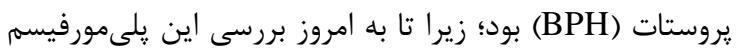

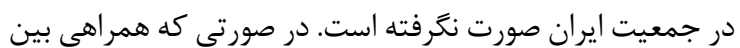

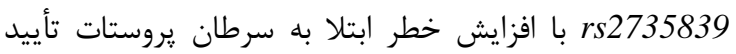

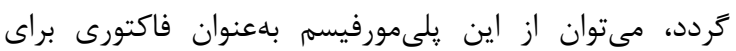
غربالكرى اين بيماران استفاده نمود.

\section{مواد و روشها}

مطالعه مورد- شاهدى حاضر شامل بـ •ا نفر از مبتلايان به

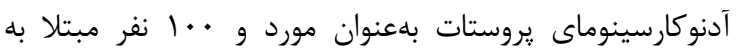

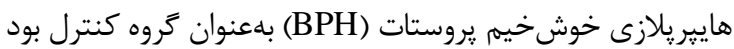

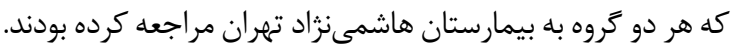
تشخيص هريك از اين دو كروه به واسطه مقدار PSA، آزمون

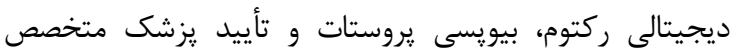

(Global cancer observatory) GLOBOCAN

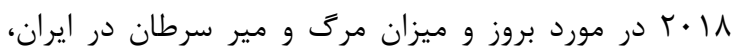

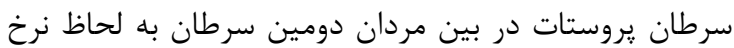

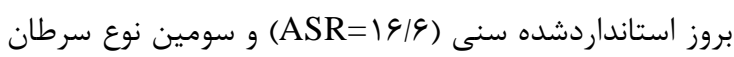

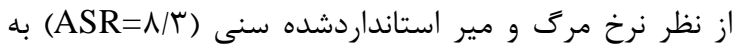

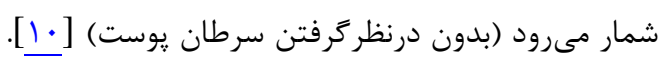

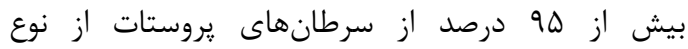

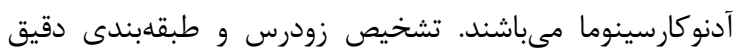
سرطان يروستات بسيار حياتى است؛ زيرا ميزان بقا در زمانى كه

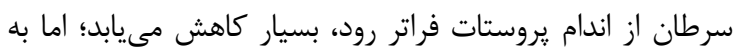

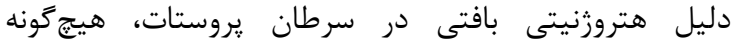

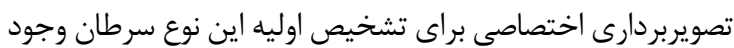

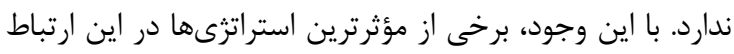

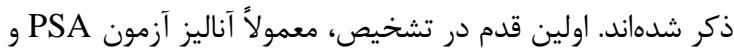
آزمون ديجيتالى ركتوم (DRE: Digital Rectal Exam)

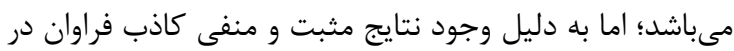

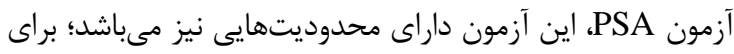

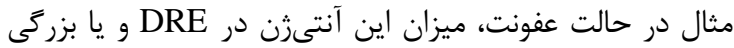

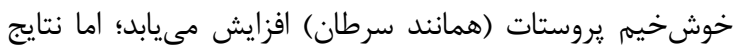

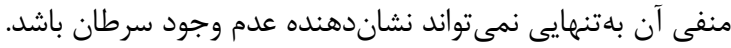

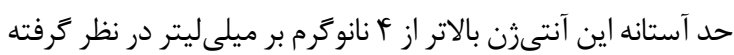

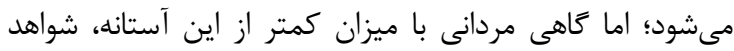

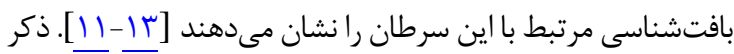
اين نكته ضرورت دارد كه بيويسى سوزنى در مراحل بين بيشرفتئه

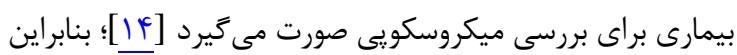

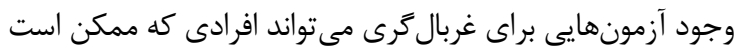

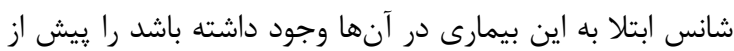

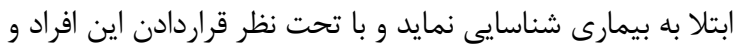

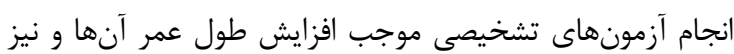

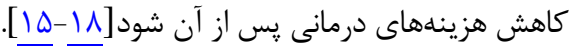

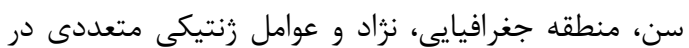

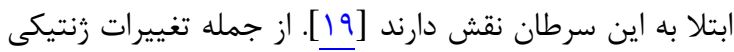

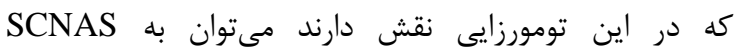
Structural ،(Somatic Copy Number Alterations) Single ) SNPs ‘Point Mutations ،Rearrangement miRNA و (Nucleotide Polymorphisms

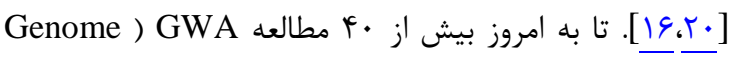
(Wide Association

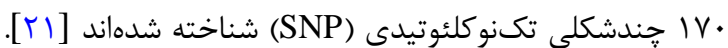

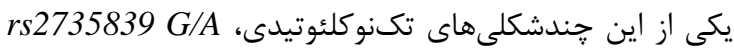

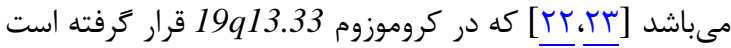

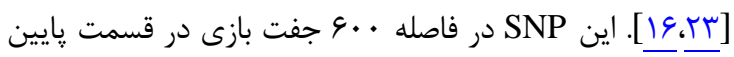
منطقه غيرترجمهشونده (3) 'Untranslated Region) زن كاما-

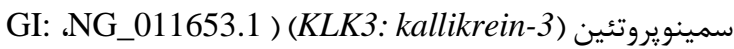


خارجى و دو يرايمر اختصاصى داخلى مىباشد. توالى يرايمرها در جدول ا مشاهده مىشود. در اين PCR حداكثر سه باند ايجاد مى مر ددد. اندازه محصول

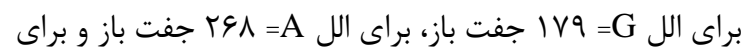

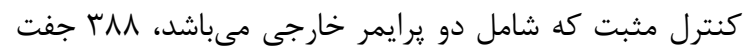

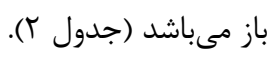

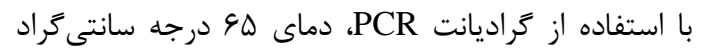

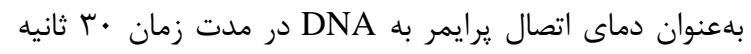
انتخاب ترديد. واكنش PCR در حجم نهايى له به ميكروليتر صورت گرفت كه هر ويال آن حاوى ميكس (A) DNA Polymerase 2x Master Mix RED-)

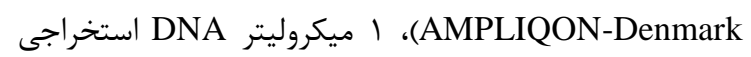

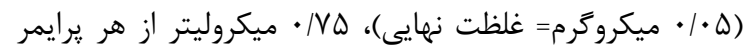

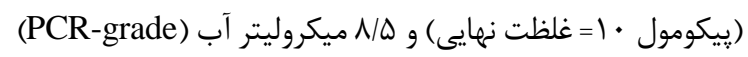

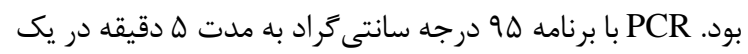

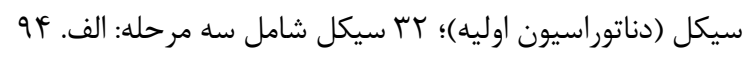

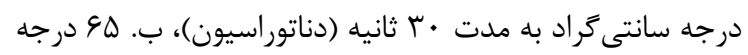

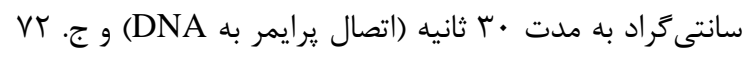

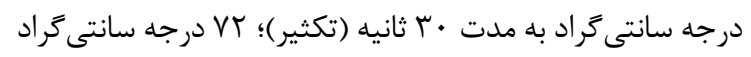

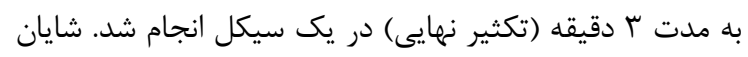

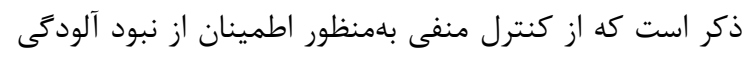

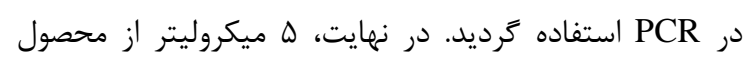
بCR

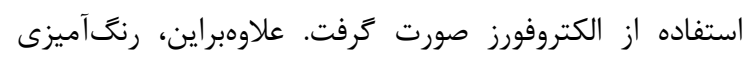

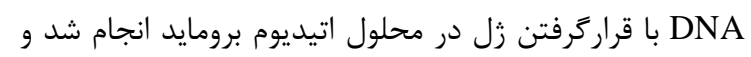

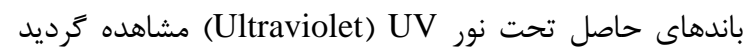

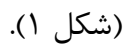

صورت كرفت و تنها بيماران مبتلا به سرطان يروستات از نوع

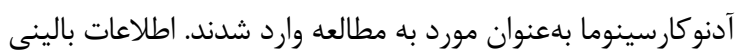

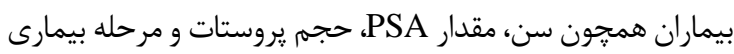

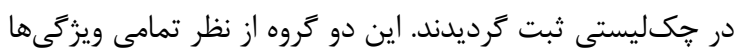
بهجز نوع بيمارى يا اختلال در يروستات مشابه بودند و سابقه ابتلا

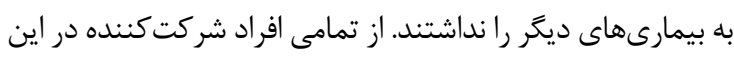
مطالعه، رضايت آكاهانه مبنى بر شركت در در مطالعه و و عدم افشاى رئن

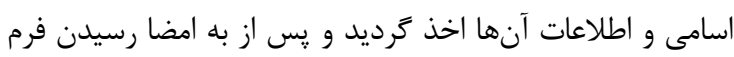

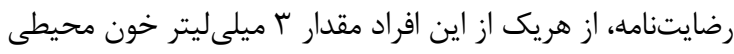

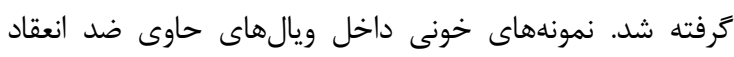
(Ethylenediaminetetraacetic Acid) EDTA شدند و در دماى • ·- درجه سانتى

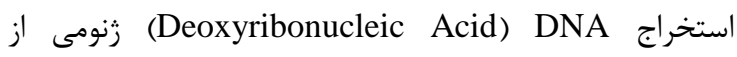

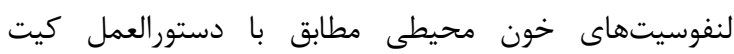
استخراجى FAVORGENE-Taiwan (يكتا تجهيز ازما، تهران، ايران) صورت كرفت. كيفيت DNA استخراجى از نظر

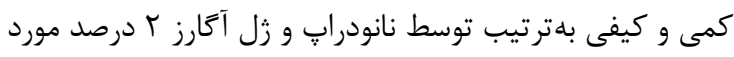

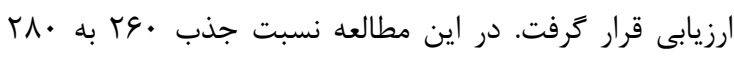

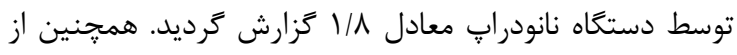
روش Tetra-primer ARMS-PCR بهمنظور تعيين زنوتايب هريك از افراد شركت كننده براى بلىمورفيسم

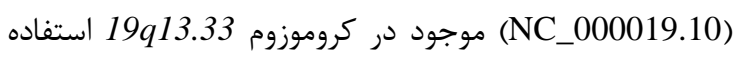

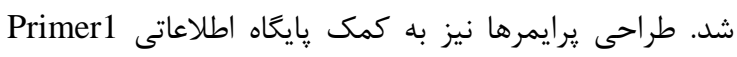

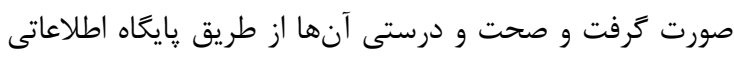
Primer-BLAST-NCBI

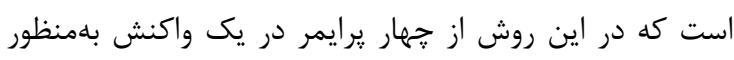

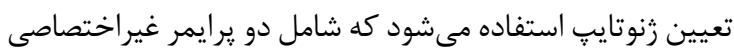

جدول ا: توالى :رايمرها و دماى ذوب هريك از آنها

\begin{tabular}{|c|c|c|c|}
\hline دماى ذوب & طول يرايمر & 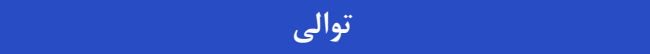 & يرايمر \\
\hline $9 V / 94$ & rV & CTGTTAGCATGAATCATCTGGCACGGCC & Forward outer \\
\hline $9 \wedge / 9 \wedge$ & rᄉ & TAACCTCAGGGTGGGAATTCCTCCAGCA & Reverse outer \\
\hline $99 / 49$ & r. & GCCTAGGGATCTGGTTCTGTCTTGTGGACG & Forward inner \\
\hline$\varepsilon \wedge / \cdot V$ & rq & CCTTCTTGGGATAGCCCCATGGTCCAATT & Reverse inner \\
\hline
\end{tabular}

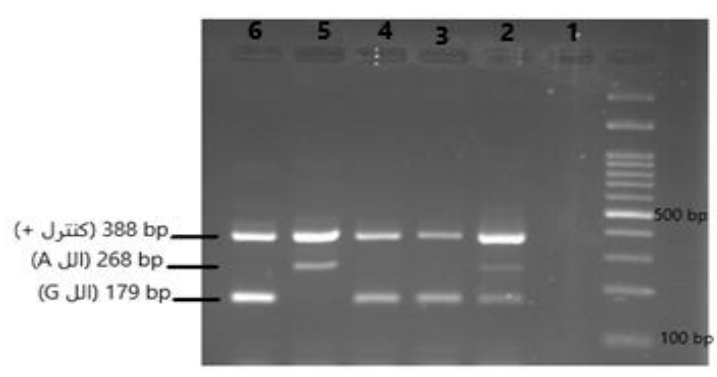

شكل ا: زل آكارز Tetra-ARMS-PCR: ماركر . إ جفت بازى (1: كنترل منفى؛ ז: زنوتيب هتروزيكوت (AG)؛

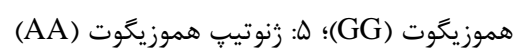

جدول r: محصولات يلىمورفيسم r2735839

\begin{tabular}{|c|c|c|c|}
\hline (جفت باز) & زنوتيب & الل - ل الل & برايمر ها \\
\hline 189 & GG & G & FI-RO \\
\hline r\&A & AA & A & FO-RI \\
\hline IVq/Y\&A & AG & $\mathrm{G} / \mathrm{A}$ & FI-RO/FO-RI \\
\hline rMA & - & كنترل + & FO-RO \\
\hline
\end{tabular}


شايان ذكر است كه در مطالعه حاضر تعادل هاردى- واينبرى (Hardy-Weinberg)

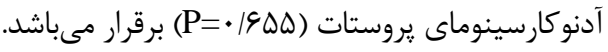

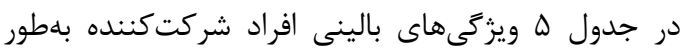

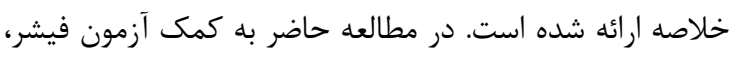

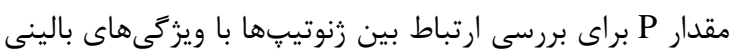

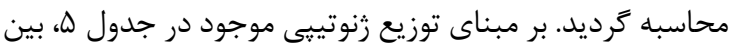
فراوانى زنوتييى يلىمورفيسم

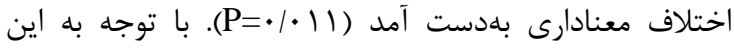

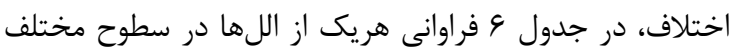
PSA ارائه شده است. مطابق با اين جدول درول در سطح سرمى

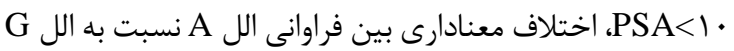

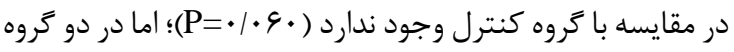

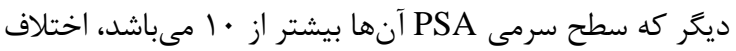

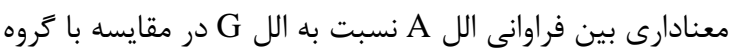

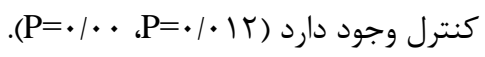

جدول ب: ويزَّى هاى دموَّرافيك افراد مورد مطالعه

\begin{tabular}{|c|c|c|}
\hline \multicolumn{2}{|c|}{ تعداد (درصد) } & متغير \\
\hline$\Lambda F(F \backslash / T)$ & $\varphi \Delta>$ & \\
\hline Vq (rN/V) & $\varepsilon \Delta-V C^{c}$ & سن (سال) \\
\hline$k \cdot(19 / 9)$ & $v \Delta \leq$ & \\
\hline$r \cdot r(1 \cdot \cdot)$ & ايرانى & قوميت \\
\hline $1.9(\Delta T / T I)$ & تهران & \\
\hline I (ID/rV) & كرج - - كرج & \\
\hline$r \pi(11 / T r)$ & بابل & \\
\hline $19(9 / \% \Delta)$ & قزوين & $\mathcal{G}$ \\
\hline $19(\mathrm{~V} / \mathrm{A} \Lambda)$ & رشت & \\
\hline$\wedge(r / q \uparrow)$ & سارى & \\
\hline
\end{tabular}

براى مقايسه فراوانى اللى و زنوتييى از آزمون كاى اسكوئر

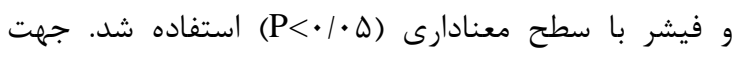
بررسى همراهى بين يلى مورفيسم و آدنوكارسينوماى يروستات

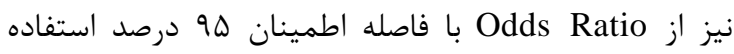

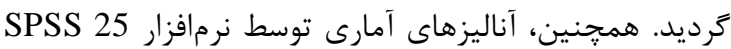

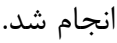

\section{يافته ها}

در اين مطالعه ץ • ا فرد مبتلا به آدنوكارسينوماى يروستات

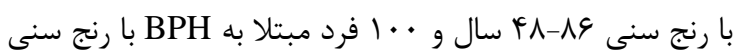
FV-N1 GV/VDIN/9|

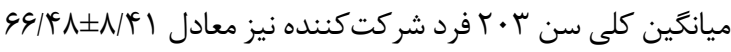
سال بلدست آمد. ساير ويزگى هاى دموگر افيك افراد شركت كنينده در مطالعه در جدول r ذكر گرديده است.

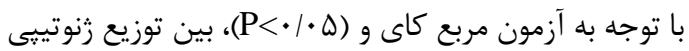

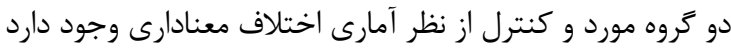

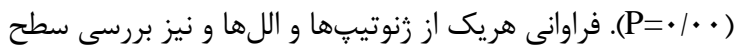

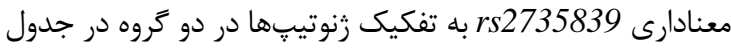

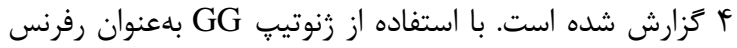

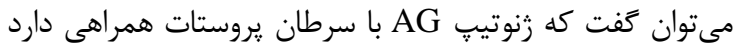

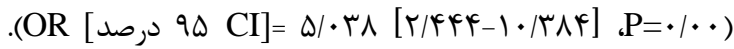
بين فراوانى زنوتيبى AG+AA در گروه آدنوكارسينوماى يروستات

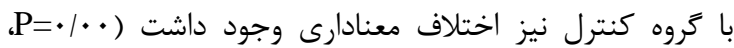

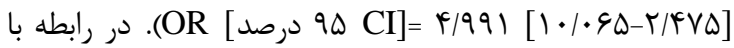
فراوانى اللى نيز آناليزهاى آمارى، تفاوت معنادارى را بين دو گركروه

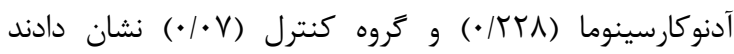

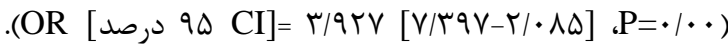

جدول fا: فراوانى زنوتيبى، اللى و بررسى همراهى يلىمورفيسم rs2735839 با بروز آدنوكارسينوماى بروستات

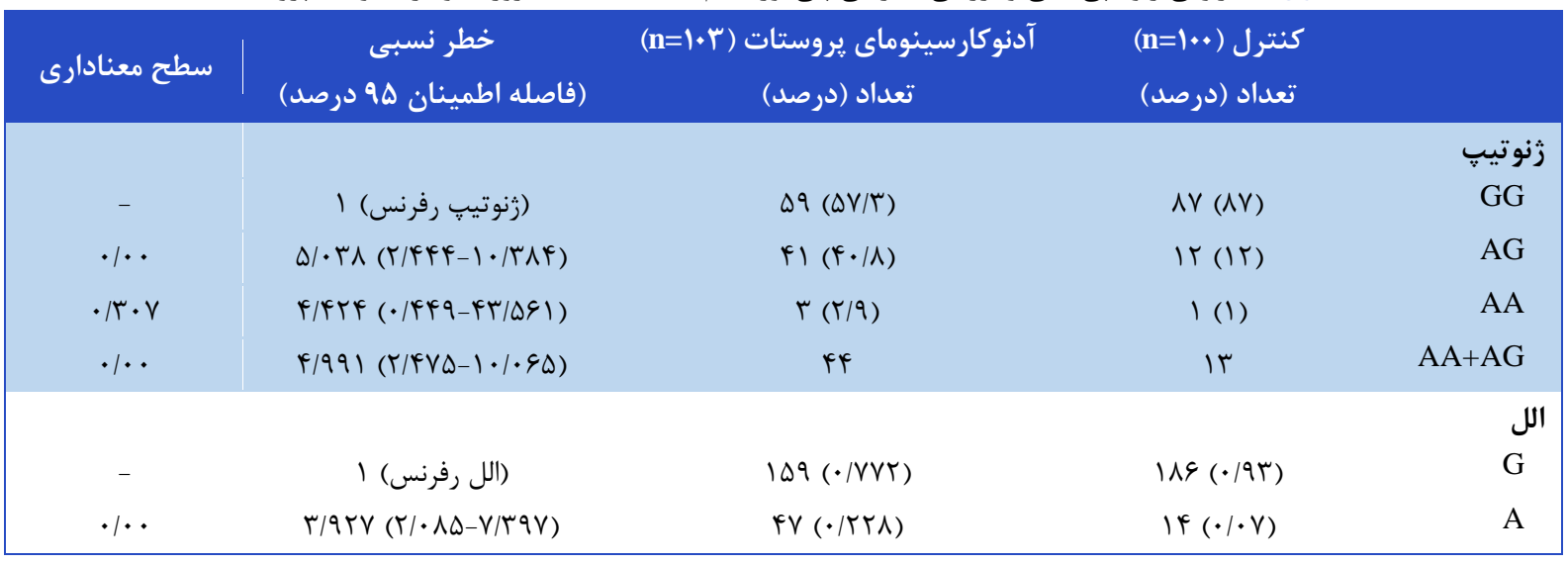

مى كند [•rs2735839 در منطقه بين زنى ميان زنهاى (كLSA

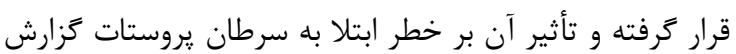

خانواده زنى Kallikrein) KLK شامل ها زن است كه در

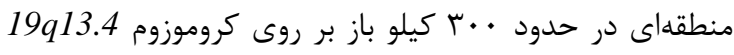

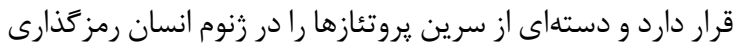


جدول ه: ارتباط بين رنوتيههاى rs2735839 با ويزَى هاى بالينى افراد شركت كننده

\begin{tabular}{|c|c|c|c|c|c|}
\hline سطح معنادارى & تعداد (درصد) GG & تعداد (درصد) AG & تعداد (درصد) AA & & \\
\hline \multirow{3}{*}{.$/ 194$} & $Q \Delta(V V / F)$ & $19(T Y / 9)$ & $\cdot(\cdot)$ & $9 \Delta>$ & \multirow{3}{*}{ سن (سال) } \\
\hline & $\Delta \varphi(V \cdot / 9)$ & $r \mid(Y \& \mid \varphi)$ & $r(r / \Delta)$ & $\varphi \Delta-V \varphi$ & \\
\hline & $r \Delta(\Phi T / \Delta)$ & $\mathbb{I}(\Psi T / Q)$ & $r(\Delta)$ & $v \Delta \leq$ & \\
\hline \multirow{3}{*}{$\cdot 1 \cdot 1$} & $9 \wedge(\vee \Delta / \mathcal{F})$ & rT $(Y Y / Q)$ & $\cdot(\cdot)$ & $1 \cdot>$ & \multirow{3}{*}{ 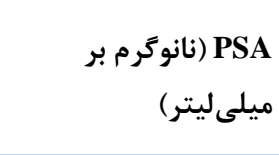 } \\
\hline & r^ $(99 / V)$ & $1 \cdot(Y M / \Lambda)$ & $f(9 / \Delta)$ & $1 \cdot-r \cdot$ & \\
\hline & $r \cdot(\Phi Y / \Delta)$ & $11(r \Delta / \Delta)$ & $\cdot(\cdot)$ & $r \cdot<$ & \\
\hline \multirow{3}{*}{$\cdot / \& \wedge \Lambda$} & $V(\Delta \cdot)$ & $\vee(\Delta \cdot)$ & $\cdot(\cdot)$ & $9-V$ & \multirow{3}{*}{ Gleason score } \\
\hline & ए (99) & $10(\Pi / / 9)$ & $1(Y / 1)$ & $\checkmark$ & \\
\hline & $r)(\Delta \cdot)$ & $19(F \Delta / T)$ & $r(F / \Lambda)$ & $\vee-1$ & \\
\hline \multirow{2}{*}{$\cdot 19}$. & $r V(\Delta \varphi / q)$ & $r \Delta(r N / \Delta)$ & $r(\boldsymbol{F} / 9)$ & مثبت & \multirow{2}{*}{ Perineural invasion } \\
\hline & $r T(\Delta V / q)$ & $19(F T / 1)$ & $\cdot(\cdot)$ & منفى & \\
\hline \multirow{2}{*}{. IOTV } & $11(91 / 1)$ & $9(\Gamma / \mu)$ & $1(\Delta / \varphi)$ & مثبت & \multirow{2}{*}{$\begin{array}{r}\text { Extraprostatic } \\
\text { extension }\end{array}$} \\
\hline & $\& \wedge(\Delta \varphi / \Delta)$ & $r \Delta(F \mid / T)$ & $r(T / Y)$ & منفى & \\
\hline
\end{tabular}

جدول 9: همراهى فراوانى اللى

\begin{tabular}{|c|c|c|c|c|}
\hline سطح معنادارى & خطر نسبى (فاصله اطمينان ه9 درصد) & G & $\mathbf{A}$ & \\
\hline & & & & كنترل \\
\hline- & (الل رفرنس) & 119 & If & PSA \\
\hline $.1 \cdot 9$ & 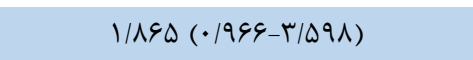 & tra & rt & $<1$. \\
\hline$\cdot / \cdot$ & r/\&YT (I/V•V-V/\&৭r) & 99 & 11 & $1 \cdot-r+$ \\
\hline.$/ .14$ & 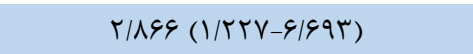 & DI & 11 & $>r$. \\
\hline
\end{tabular}

مطالعه حاضر ارتباط بين زنوتيبهاى rs2735839 با ويزگى هاى

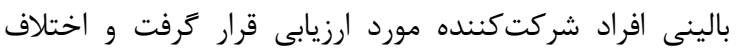

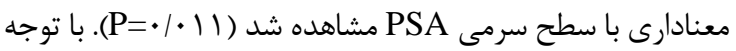

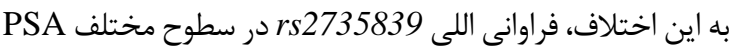

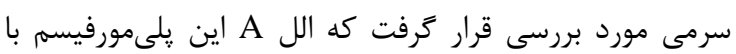

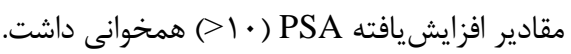

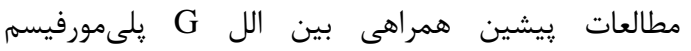

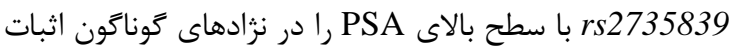
كردهاند؛ اما با اين وجود، ارتباط اين يلى بلى بورفيسم با سرطان

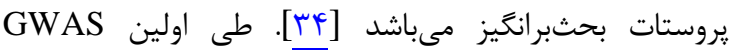
كه توسط ايلس و (Genome Wide Association Study) همكاران انجام شد، rs2735839 بهعنوان فاكتور خطر در رابطه

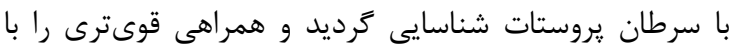

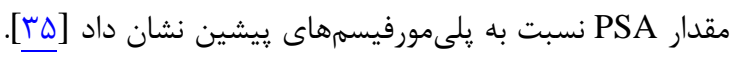

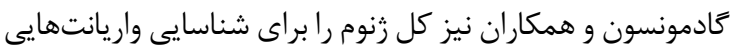

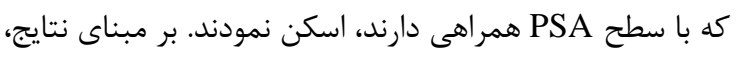

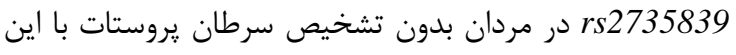
فنوتيٍ بسيار مرتبط بود [عس].

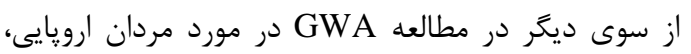

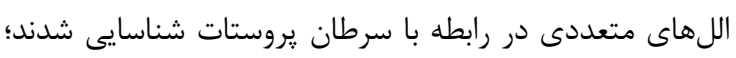

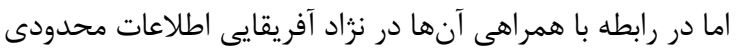

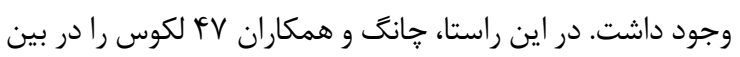

شده است. اين يلىمورفيسم در محدوده . .9 جفت باز پإيين دست

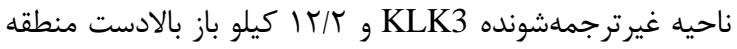

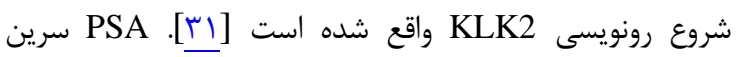

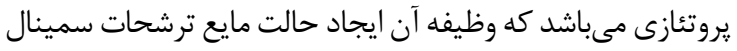

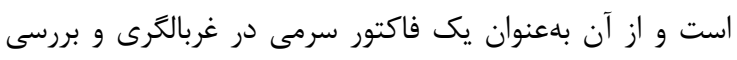

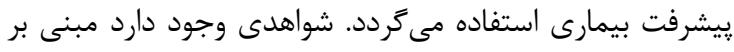

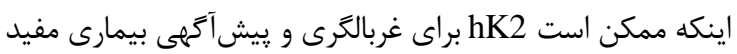
باشد [بr]. فعاليت بيش از حد

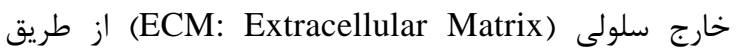
فعالسازى 2 Pro-Matrix Metalloproteinase مى كردود. علاوهبراين، اين زن سبب فعال سازى فاكتور رشد تومور

(TGF: Transforming growth factor) در مطالعه حاضر فراوانى يلىمورفيسم rs2735839 در گروه

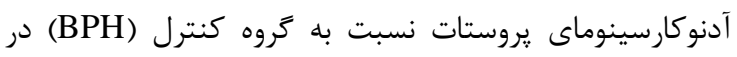

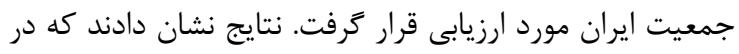

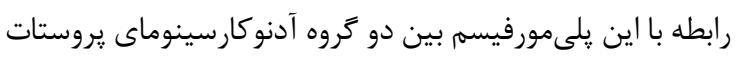

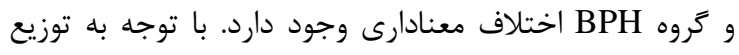

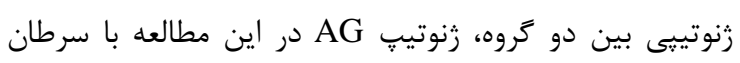

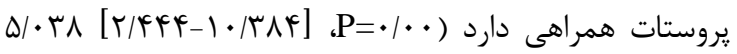

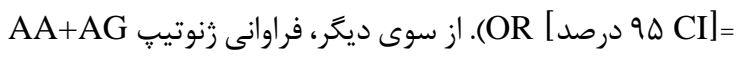

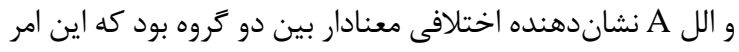
ناشى از همراهى الل A با اين سرطان مئدياشد. علاوهبراين، در 
در نتيجه لازم است براى درمانهاى تهاجمى، بيشتر مورد

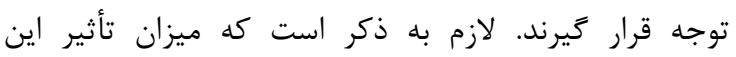

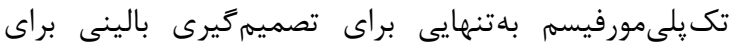

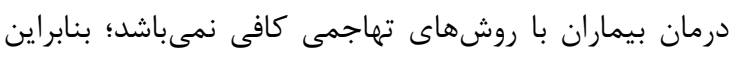

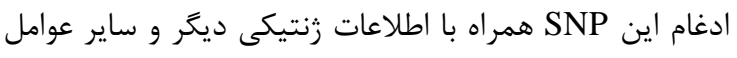

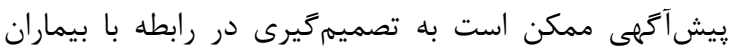

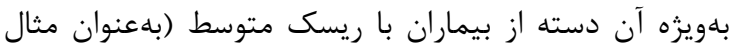

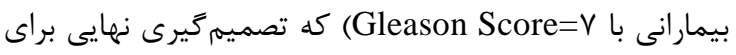

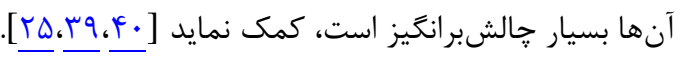

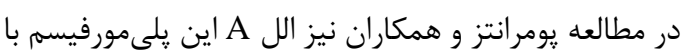

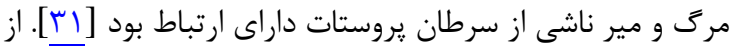

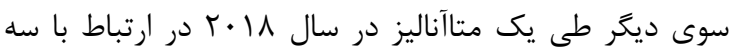

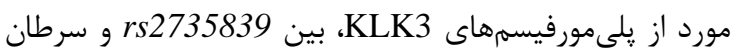

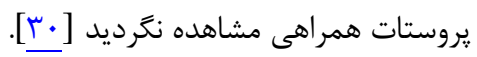

\section{نتيجه كيرى}

نتايج مطالعه حاضر در ارتباط با rs2735839 نشاندهنده همراهى اين يلىمورفيسم با خطر سرطان يروستات در جمعيت ايران

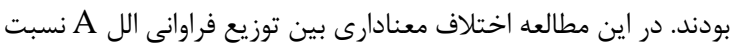

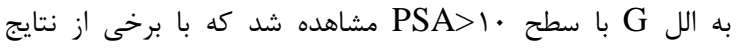

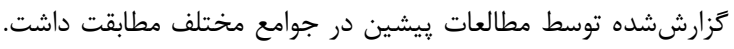

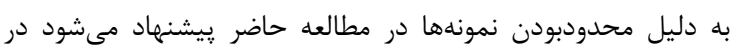

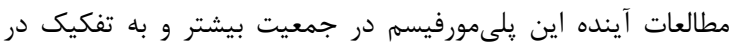
هريك از نزادهاى موجود در ايران بررسى كردند

\section{تشكر و قلر داذى ماذى}

مقاله حاضر بركرفته از پاياننامه كارشناسى ارشد زنتيك در

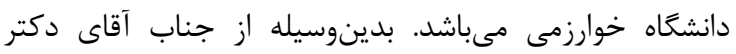

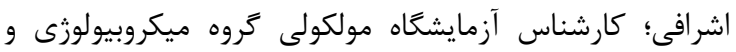

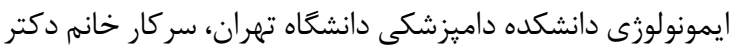

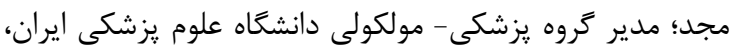

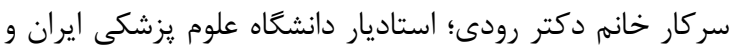

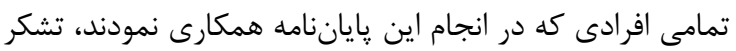

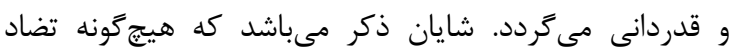
منافعى در مطالعه حاضر ززارش نشده است.

\section{REFERENCES}

1. Pernar $\mathrm{CH}$, Ebot EM, Wilson KM, Mucci LA. The epidemiology of prostate cancer. Cold Spring Harb Perspect Med. 2018;8(12):a030361. PMID: 29311132 DOI: 10.1101/cshperspect.a030361

2. Hassanipour $S$, Fathalipour M, Salehiniya $H$. The incidence of prostate cancer in Iran: a systematic review and metaanalysis. Prostate Int. 2018;6(2):41-5. PMID: 29922630 DOI: $10.1016 /$ j.prnil.2017.11.003

3. Rafiemanesh $\mathrm{H}$, ghoncheh $\mathrm{M}$, salehiniya $\mathrm{H}$, mohammadian HA. Epidemiology of prostate cancer and its incidence trends in Iran. J Sabzevar Univ Med Sci. 2016;23(2):320-7. [Persian]

4. Taitt HE. Global trends and prostate cancer: a review of incidence, detection, and mortality as influenced by race, ethnicity, and geographic location. Am J Mens Health. 2018;12(6):1807-23. PMID: 30203706 DOI: 10.1177/
نفر مورد ارزيابى قرار دادند و گزارش نمودند كه الل خطر

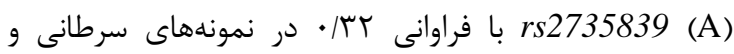

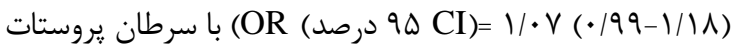
همراهى ندارد [بV]. در اين راستا در مطالعهاى در زإين مبنى بر همراهى اين

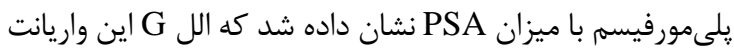
با افزايش سطح سرمى PSA ارتباط دارد كه اين مهرم با نتايج

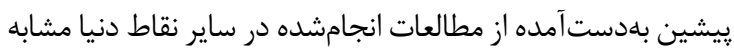

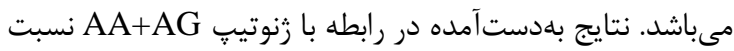
به همراهى الل G با افزايش مقدار PSA، مغاير با نتايج مطالعه حاضر

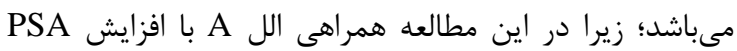
مشاهده گرديد [سب].

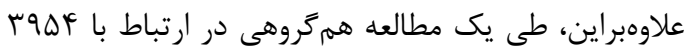

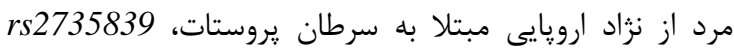

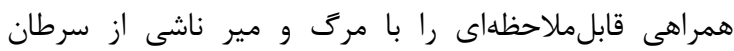

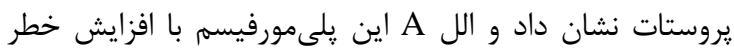

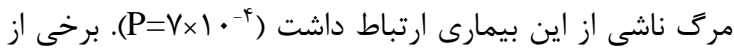

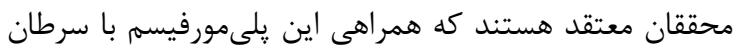

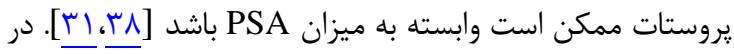

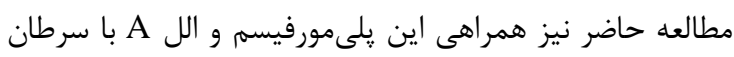
در جمعيت ايران اثبات كرديد. مشكل اصلى در مديريت بالينى بيماران مبتلا به سرطان آندان

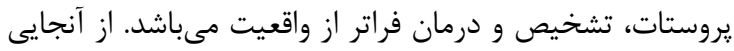

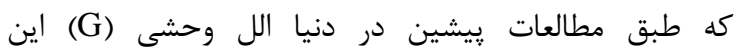
يلىمورفيسم با افزايش سطح PSA و افزايش احتمال ابتلا به ديه

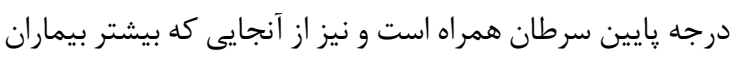

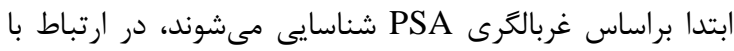

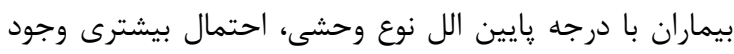

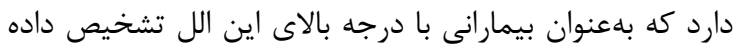

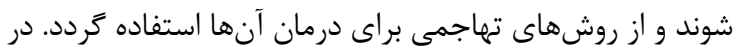

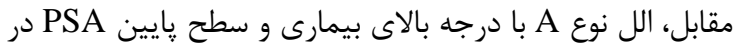

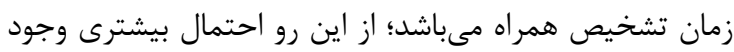

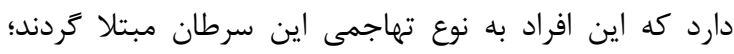

\section{9}

5. Zhou CK, Check DP, Lortet-Tieulent J, Laversanne M, Jemal A, Ferlay $\mathbf{J}$, et al. Prostate cancer incidence in 43 populations worldwide: an analysis of time trends overall and by age group. Int $J$ Cancer. 2016;138(6):1388-400. PMID: 26488767 DOI: $10.1002 / \mathrm{ijc} .29894$

6. Pakzad R, Mohammadian-Hafshejani A, Ghoncheh M, Pakzad I, Salehiniya H. The incidence and mortality of prostate cancer and its relationship with development in Asia. Prostate Int. 2015;3(4):135-40. PMID: 26779461 DOI: 10.1016/j.prnil.2015.09.001

7. Hassanipour S, Namvar G, Fathalipour M, Salehiniya H. The incidence of kidney cancer in Iran: a systematic review and meta-analysis. Biomedicine. 2018;8(2):9. PMID: 29806587 DOI: $10.1051 / \mathrm{bmden} / 2018080209$ 
8. Haas GP, Delongchamps N, Brawley OW, Wang CY, de la Roza G. The worldwide epidemiology of prostate cancer: perspectives from autopsy studies. Can J Urol. 2008; 15(1):3866-71. PMID: 18304396

9. Pakzad R, Rafiemanesh H, Ghoncheh M, Sarmad A, Salehiniya H, Hosseini S, et al. Prostate cancer in Iran: trends in incidence and morphological and epidemiological characteristics. Asian Pac J Cancer Prev. 2016;17(2):839-43. PMID: 26925689

10. Ferlay J, Ervik M, Lam F, Colombet M, Mery L, Piñeros M, et al. Global cancer observatory: cancer today. Lyon, France: International Agency for Research on Cancer; 2018.

11. Bell KJ, Del Mar C, Wright G, Dickinson J, Glasziou P. Prevalence of incidental prostate cancer: a systematic review of autopsy studies. Int J Cancer. 2015;137(7):1749-57. PMID: 25821151 DOI: 10.1002/ijc.29538

12. Hughes C, Murphy A, Martin C, Sheils O, O'Leary J. Molecular pathology of prostate cancer. J Clin Pathol. 2005;58(7):673-84. DOI: 10.1136/jcp.2002.003954

13. Grignon DJ, Sakr WA. Zonal origin of prostatic adenocarcinoma: are there biologic differences between transition zone and peripheral zone adenocarcinomas of the prostate gland? J Cell Biochem Suppl. 1994;19:267-9. PMID: $\underline{7823599}$

14. Tian JY, Guo FJ, Zheng GY, Ahmad A. Prostate cancer: updates on current strategies for screening, diagnosis and clinical implications of treatment modalities. Carcinogenesis. 2017;39(3):307-17. PMID: 29216344 DOI: 10.1093/carcin/ bgx141

15. Ao X, Liu Y, Bai XY, Qu X, Xu Z, Hu G, et al. Association between EHBP1 rs721048 (A> G) polymorphism and prostate cancer susceptibility: a meta-analysis of 17 studies involving 150,678 subjects. Onco Targets Ther. 2015;8:1671-80. PMID: 26185455 DOI: $10.2147 /$ OTT.S84034

16. Wallis CJ, Nam RK. Prostate cancer genetics: a review. EJIFCC. 2015;26(2):79-91. PMID: 27683484

17. McLean MH, El-Omar EM. Genetics of gastric cancer. Nat Rev Gastroenterol Hepatol. 2014;11(11):664-74. PMID: 25134511 DOI: 10.1038/nrgastro.2014.143

18. Zhao CX, Liu M, Xu Y, Yang K, Wei D, Shi XH, et al. 8q24 rs 4242382 polymorphism is a risk factor for prostate cancer among multi-ethnic populations: evidence from clinical detection in China and a meta-analysis. Asian Pac J Cancer Prev. 2014;15(19):8311-7. PMID: 25339022

19. Alvarez-Cubero MJ, Saiz M, Martinez-Gonzalez LJ, Alvarez JC, Lorente JA, Cozar JM. Genetic analysis of the principal genes related to prostate cancer: a review. Urol Oncol. 2013;31(8):1419-29. PMID: 23141781 DOI: 10.1016/j. urolonc.2012.07.011

20. Bethel CR, DeMarzo AM, Nelson WG. Molecular pathogenesis of prostate cancer: somatic, epigenetic, and genetic alterations. Mol Pathol. 2009;12:489-500. DOI: 10.1016/B978-0-12-374419-7.00024-X

21. Benafif S, Kote-Jarai Z, Eeles RA. A review of prostate cancer genome-wide association studies (GWAS). Cancer Epidemiol Biomarkers Prev. 2018;27(8):845-57. PMID: 29348298 DOI: 10.1158/1055-9965.EPI-16-1046

22. Ahmed M, Dorling L, Kerns S, Fachal L, Elliott R, Partliament $\mathrm{M}$, et al. Common genetic variation associated with increased susceptibility to prostate cancer does not increase risk of radiotherapy toxicity. Br J Cancer. 2016;114(10):1165-74. PMID: 27070714 DOI: $10.1038 /$ bjc.2016.94

23. Kote-Jarai Z, Al Olama AA, Leongamornlert D, Tymrakiewicz M, Saunders E, Guy M, et al. Identification of a novel prostate cancer susceptibility variant in the KLK3 gene transcript. Hum Genet. 2011;129(6):687-94. PMID: 21465221 DOI: $10.1007 / \mathrm{s} 00439-011-0981-1$

24. Hsu FC, Sun J, Wiklund F, Isaacs SD, Wiley KE, Purcell LD, et al. A novel prostate cancer susceptibility locus at $19 \mathrm{q} 13$. Cancer Res. 2009;69(7):2720-3. PMID: 19318570 DOI: 10.1158/0008-5472.CAN-08-3347

25. He Y, Gu J, Strom S, Logothetis CJ, Kim J, Wu X. The prostate cancer susceptibility variant rs2735839 near KLK3 gene is associated with aggressive prostate cancer and can stratify gleason score 7 patients. Clin Cancer Res. 2014;20(19):5133-9. PMID: 25274378 DOI: 10.1158/10780432.CCR-14-0661

26. Parikh H, Wang Z, Pettigrew KA, Jia J, Daugherty S, Yeager $\mathrm{M}$, et al. Fine mapping the KLK3 locus on chromosome 19q13. 33 associated with prostate cancer susceptibility and PSA levels. Hum Genet. 2011;129(6):675-85. DOI: 10.1007/s00439-011-0953-5

27. Mattsson JM, Ravela S, Hekim C, Jonsson M, Malm J, Närvänen A, et al. Proteolytic activity of prostate-specific antigen (PSA) towards protein substrates and effect of peptides stimulating PSA activity. PLoS One. 2014;9(9):e107819. PMID: 25237904 DOI: 10.1371/journal.pone.0107819

28. LeBeau AM, Singh P, Isaacs JT, Denmeade SR. Prostatespecific antigen is a "chymotrypsin-like" serine protease with unique P1 substrate specificity. Biochemistry. 2009; 48(15):3490-6. PMID: 19281249 DOI: $10.1021 / b i 9001858$

29. Chen C, Xin Z. Single-nucleotide polymorphism rs1058205 of KLK3 is associated with the risk of prostate cancer: a casecontrol study of Han Chinese men in Northeast China. Medicine. 2017;96(10):e6280. PMID: 28272245 DOI: 10.1097/MD.0000000000006280

30. Ding WH, Ren KW, Yue C, Zou JG, Zuo L, Zhang LF, et al. Association between three genetic variants in kallikrein 3 and prostate cancer risk. Biosci Rep. 2018;38(6):BSR20181151. PMID: 30413614 DOI: 10.1042/BSR20181151

31. Pomerantz MM, Werner L, Xie W, Regan MM, Lee GS, Sun $\mathrm{T}$, et al. Association of prostate cancer risk loci with disease aggressiveness and prostate cancer-specific mortality. Cancer Prev Res. 2011;4(5):719-28. PMID: 21367958 DOI: 10.1158/1940-6207.CAPR-10-0292

32. Liu H, Wang B, Han C. Meta-analysis of genome-wide and replication association studies on prostate cancer. Prostate. 2011;71(2):209-24. PMID: 20690139 DOI: 10.1002/pros.21235

33. Nobata S, Hishida A, Naito M, Asai Y, Mori A, Kuwabara $\mathrm{M}$, et al. Association between KLK3 rs2735839 G/A polymorphism and serum PSA levels in Japanese men. Urol Int. 2012;89(1):39-44. PMID: 22433834 DOI: 10.1159/ $\underline{000332197}$

34. Severi G, Hayes VM, Neufing P, Padilla EJ, Tilley WD, Eggleton SA, et al. Variants in the prostate-specific antigen (PSA) gene and prostate cancer risk, survival, and circulating PSA. Cancer Epidemiol Biomarkers Prev. 2006;15(6):11427. PMID: 16775173 DOI: $10.1158 / 1055-9965 . E P I-05-0984$

35. Eeles RA, Kote-Jarai Z, Giles GG, Al Olama AA, Guy M, Jugurnauth SK, et al. Multiple newly identified loci associated with prostate cancer susceptibility. Nat Genet. 2008;40(3):316-21. PMID: 18264097 DOI: 10.1038/ng.90

36. Gudmundsson J, Besenbacher S, Sulem P, Gudbjartsson DF, Olafsson I, Arinbjarnarson S, et al. Genetic correction of PSA values using sequence variants associated with PSA levels. Sci Transl Med. 2010;2(62):62ra92. PMID: 21160077 DOI: 10.1126/scitranslmed.3001513

37. Chang BL, Spangler E, Gallagher S, Haiman CA, Henderson $\mathrm{B}$, Isaacs $\mathrm{W}$, et al. Validation of genome-wide prostate cancer associations in men of African descent. Cancer Epidemiol Biomarkers Prev. 2011;20(1):23-32. PMID: 21071540 DOI: 10.1158/1055-9965.EPI-10-0698

38. Hoffmann TJ, Van Den Eeden SK, Sakoda LC, Jorgenson E, Habel LA, Graff RE, et al. A large multiethnic genome-wide association study of prostate cancer identifies novel risk variants and substantial ethnic differences. Cancer Discov. 2015;5(8):878-91. PMID: 26034056 DOI: 10.1158/21598290.CD-15-0315

39. Penney KL, Schumacher FR, Kraft P, Mucci LA, Sesso HD, Ma J, et al. Association of KLK3 (PSA) genetic variants with prostate cancer risk and PSA levels. Carcinogenesis. 2011;32(6):853-9. PMID: 21421545 DOI: 10.1093/ carcin/bgr050

40. Gallagher DJ, Vijai J, Cronin AM, Bhatia J, Vickers AJ, Gaudet MM, et al. Susceptibility loci associated with prostate cancer progression and mortality. Clin Cancer Res. 2010;16(10):2819-32. PMID: 20460480 DOI: 10.1158/10780432.CCR-10-0028 